\title{
Delineation of the government capital with non-state capital investment in the infrastructure sector
}

\author{
Zhang Ningchuan ${ }^{1,}$, , Zhao Xinyu ${ }^{2, b}$ \\ ${ }^{1}$ Economics and Management School of Wuhan University, China \\ ${ }^{2}$ Economics and Management School of Wuhan University, China \\ a395825939@qq.com, b525832344@qq.com
}

Keywords: Government capital; Non-state capital; Infrastructure; Investors; Theoretical analysis

\begin{abstract}
Non-state capital investment in infrastructure projects has become a key link in Chinese economic reform. Whether public goods are invested by the Government or by private investors should be analyzed according to the specific circumstances. The determination of the scope of non-state capital investment should follow the principle of comparative efficiency, the principle of property rights, the range of benefit principle and responsibilities and rights of the proportionality principle. Based on the principles above, whether there is a charging mechanism is an important distinction condition, and infrastructure project area is divided into commercial, quasi-operating and non-operating items. The principal mode of operation, channels of funds and vesting of rights and interests are determined by the project's property, to ensure the effective operation of the infrastructure investment.
\end{abstract}

\section{Definition of public products and private products investment subject}

The government and the private sector in investment quantity have a reciprocal relationship. Social resources configuration between two departments, therefore, has a relationship of trading off and taking turns. As shown in figure 1, lines NG is the social resource constraints, G is the amount of social resources, the vertical axis represents the number of resource invested in the private sector, the horizontal axis shows the number of resources invested in government departments, A and B respectively represent two different kinds of combination of resource allocation. It can be seen from the diagram, while the number of social resources is fixed, resources allocation in the private sector shifts from N1 to N2, the government departments on the allocation of resources shifts from G2 to G1.

Corresponding to the resources allocation relationship is the alternate relationship in the number of products between the two departments (See Figure 2), "Production possibilities frontier" is curve ACB. Point A represents all resources concentrated on private products production, point B represents all resources invested in public goods production. Along the production possibility frontier, every increase of a certain amount of public products production will reduce the corresponding private products. In fact, the production possibilities frontier is only technical, in practice, it can't implement all of the above combinations, because the capital of investment in the production of public goods must be obtained from the tax of private sector, the tax has an efficiency cost (the higher tax, the lower production efficiency of the whole society). Government increases the supply of public goods by tax, which will reduce people's income and consumption, and also reduce private investment, and will then reduce the government's tax base. Therefore, as more and more resources are used in the production of public goods, social production possibility boundary will be cut to the location of the "production possibility boundary", namely, AHD curve in figure 2 . When private products become OE, actually cannot make the public products reach the level OF, and can only get production in OG of public products.

Figure 1

The number of exchange relationship between government and private sector in resources allocation

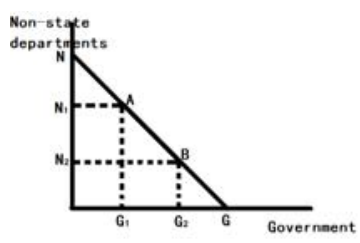


Figure 2

The alternate relationship between government and private sector in the number of goods

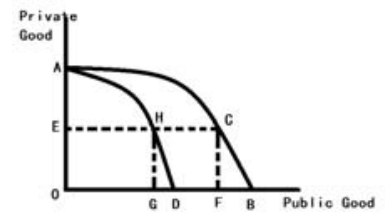

Government and non-state capital should each performs its own functions. However, the essence of the public goods attribute will also lead to low efficiency. The low efficiency shows in two aspects, namely insufficient implementation efficiency and lack of supply.

Figure 3

The loss caused by toll roads

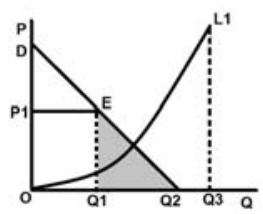

Figure 4

Charging analysis of quasi-public products

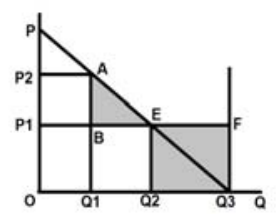

In not crowded highway, as shown in figure 3, the demand curve DQ2 is on the left of saturation point in the road (the limit of carrying capacity) Q3. If we assume that there is no maintenance costs, even if fully meet the consumer, but as long as no more than Q3, there will not cause supply cost increasing by the edge of the road, that is, without widening (or laying) new highway. Therefore charge is not due. But if the private sector operates, then to recover the investment; at least, they can only be compensated by the way of charging. The price is set atP1, and crossingvehiclesreducefromQ2toQ1, and then the welfare loss due to fees and charges is Q1toQ3, which is represented by the area of a triangleQ1Q2E, just the losses for the lack of efficiency.

At this point, we can draw the conclusions: first, public goods must be produced by government investment. Second, as noted earlier, the government investment should not be too big.

\section{Theoretical analysis of quasi-public goods investment subject}

In real life, the pure public product is only a small part of all social, a large number of public products is between private and public products (quasi-public products), and the vast majority of infrastructure belong to the category of quasi-public products. Assume that the marginal cost of the public product production is fixed, so the production cost curve is a horizontal line, namely line P1F. Charging will pay certain transaction cost, which is the figure 4 of ABP1P2rectangle area, by the charging price for P2. And the equilibrium of supply and demand moves from not charging $\mathrm{E}$ point to A point above the left. Consumption reduces from Q2 to Q1, accordingly. Obviously, this led to the lack of social benefit, which is a form of welfare losses. $\mathrm{ABE}$ is the consumer surplus of not charging in this figure, and is also consumer losses for charging. On the other hand, with no charging, consumption will be increased from Q2 to Q3 by tax concentrating resources and supplying for free. Therefore, part of the cost of production (EFQ3 triangle area) cannot be compensated, and production is unsustainable. So in the case of no charging, it can only be compensated for this part through the increasing of tax. And the realization of the tax need to pay transaction costs, especially when the government investment field of "preferred" is too wide, the welfare loss is quite considerable. Therefore, for this kind of quasi-public products, whether to charge or not, there is a dilemma. In many cases, the value to judgment according to which the loss is small determines the way should be taken.

\section{Delineating standards of government and non-state capital investment in infrastructure}

\section{Operating infrastructure projects}

These projects have charging mechanism, capital inflow and efficient allocation of through the market. The motivation and purpose of them are to make profit maximization; the formation of the investment process is a value-added process, and can be achieved through social investment. Non-state capital investment in such projects must be in line with the development plans and industrial-oriented policies. 


\section{Quasi-operational infrastructure projects}

Such projects have charging mechanism and capital inflows, and have the potential profit, but the policy is not in place and other objective factors, unable to recover the cost of the project, with part of the public welfare, and is the market failure and inefficient part, because of their non-obvious economic benefits, the results of the operation of the market will inevitably form the gap in the supply of funds to maintain operations through the government appropriate discount or policies of preferential, and let the price gradually put in place and when conditions are ripe, it can be converted into business projects.

\section{Non-operating infrastructure projects}

Such projects are without charging mechanism, capital inflows. This is the part of market failure and the effective portion of the government, and its purpose is to obtain social and environmental benefits, market regulation is difficult to work on this kind of investment, only by the government on behalf of the public interest financial commitments, according to the government investment mode of operation, sources of funding should mainly be government financial input, and with a fixed taxes or charges as a guarantee. Of course, its interests are owned by the government. However, in the course of the operation of the investment, the introduction of competition mechanism is needed, by tendering system operation and strives to improve the investment decisions more scientific, normative, and promote the further investment returns.

\section{Summary}

In recent years, a large number of private funds is in a "sleep" state, eager to find a way out. Huge non-state capital is not valid to enter the field of investment, but over into the processing industry, resulting in a series of adverse effects; at the same time, there is an urgent need for capital infrastructure sectors, but are subjected to a variety of entry into restricted.

The hot money problem is the hotspot, coincides with this year's the National People's Congress and the Chinese Political Consultative Conference(NPC\&CPPCC), stressing the need to relax the field and scope of non-state capital investment, the introduction of $<$ Several Opinions of the State Council to encourage and guide non-state investment in health development> encourages and guides private capital into the basic infrastructure fields. Non-state capital entering into the field of infrastructure has become a new topic of the times. As a result, we have started the thinking of non-state capital investment in infrastructure field.

China's economic development relies heavily on investment booming, the following table shows the rapid increase of the amount of investment in recent years. In the sources of investment funds, self-financing is the most important part, with a greater proportion than the state budget funds and other sources of funding, and the growth rate is significantly in primacy. It also reflects the necessity trend of private capital into infrastructure sector.

Table1

Investment in Fixed Assets (Excluding Rural Households) by Sources of Funds and by Jurisdiction of Management

\begin{tabular}{cccccc}
\hline \hline Year & & & & & \\
& StateBudget & Domestic Loans & ForeignInvestment & Self-raisingFunds & Others \\
\hline 2005 & 3637.9 & 15363.9 & 3386.4 & 44154.5 & 14369.7 \\
2006 & 4438.7 & 18814.8 & 3811.0 & 56547.5 & 18147.0 \\
2007 & 5464.1 & 22136.1 & 4549.0 & 74520.9 & 24073.3 \\
2008 & 7377.0 & 25466.0 & 4695.8 & 97846.5 & 23194.4 \\
2009 & 11493.6 & 37634.1 & 3983.5 & 127557.7 & 38117.7 \\
2010 & 13104.7 & 45104.7 & 4339.6 & 165752.0 & 44823.6 \\
2011 & 14843.4 & 46034.8 & 5062.0 & 220860.2 & 50094.8 \\
\hline \hline
\end{tabular}

Both theoretical support and practice proved non-state capital entering into the field of infrastructure is a win-win behavior, not only in line with the principle of optimal economy, but also in line with the trend of the times, so it has great economic significance and social value. We have reason to believe that non-state capital entering into infrastructure sector, will be fully demonstrated the ability, enabling China's infrastructure construction entering a new era, driving the sustainable development of China's economy .

\section{References}

[1] Krueger Jr, Norris F. "The Cognitive Infrastructure of Opportunity Emergence*." Entrepreneurship. Springer Berlin Heidelberg, 2007. 185-206.

[2] Reese, George. Cloud Application Architectures: Building Applications and Infrastructure in the Cloud. O'Reilly Media, 2009. 
[3] Quiñones, Carlos García, et al. "Mitosis compiler: an infrastructure for speculative threading based on pre-computation slices." ACM Sigplan Notices. Vol. 40. 2005.

[4] Francois, Joseph. "Institutions, infrastructure, and trade." World Bank Policy Research Working Paper 4152 (2007).

[5] McDonald, Clement J., et al. "The Indiana network for patient care: a working local health information infrastructure." Health Affairs 24.5 (2005): 1214-1220.

[6] Zhuang, Shelley, et al. "Host mobility using an internet indirection infrastructure." Wireless Networks 11.6 (2005): 741-756.. 